\title{
When Dementia is in the House: Needs Assessment Survey for Young Caregivers
}

\author{
Katherine R. Nichols, David Fam, Cheryl Cook, Michelle Pearce, Gail Elliot, \\ Sylvia Baago, Kenneth Rockwood, Tiffany W. Chow
}

\begin{abstract}
Objective: To learn more about the needs and experiences of young carers for patients of frontotemporal dementia (FTD) in order to create a relevant support website for young caregivers to dementia patients. Methods: Two focus groups were held with a total of fourteen young carers aged 11-18. The data corpus was collected through a semi-structured interview facilitated by a medical journalist who had prior experience as a caregiver to a patient with FTD. The transcripts were narrowed to a dataset for descriptive analysis using a coding scheme to reveal the main themes of their responses. Results: Seven overlapping theme areas were: emotional impact of living with a parent with FTD, caregiving, coping, symptoms, diagnosis, relationships, and support. Based on the participants` responses, a website was launched providing supportive information and counsel for young carers. Conclusion: Young carers saw the experience of caring for a parent with early-onset dementia as positive overall, but identified opportunities for professionals to assist them in overcoming stigma and the challenge of balancing childhood and adolescent development within this context.
\end{abstract}

RÉSUMÉ: Présence de démence au domicile : enquête sur l'évaluation des besoins des soignants qui sont jeunes. Objectif : Le but de l'étude était d'en apprendre davantage sur les besoins et les expériences des soignants qui sont jeunes et qui aident aux soins de patients atteints de démence frontotemporale (DFT) afin de créer un site Internet de soutien qui soit pertinent pour les soignants qui sont jeunes et qui prennent soin de patients qui sont déments. Méthode : Deux groupes de discussion composés en tout de 14 jeunes se sont réunis pour en discuter. Les données a été recueillies au moyen d'une entrevue semi-structurée dont le modérateur était un journaliste médical qui avait acquis de l'expérience en tant que soignant d'un patient atteint de DFT. Les informations transcrites ont été limitées à des données adaptées à une analyse descriptive utilisant un système de codage afin de déceler les thèmes principaux des réponses. Résultats : Les sept thèmes qui se chevauchaient étaient les suivants : l'impact émotionnel du fait de vivre avec un parent atteint de DFT, de lui prodiguer des soins, l'adaptation, les symptômes, le diagnostic, les relations et le soutien. Les réponses des participants ont servi à bâtir un site Internet qui fournit des renseignements pratiques et des conseils aux jeunes qui aident à prendre soin de patients atteints de DFT. Conclusion : Les jeunes aidants considéraient que leur expérience auprès d'un parent atteint de démence à début précoce était positive en général, mais ils ont identifié des domaines où les professionnels pourraient les aider, afin de surmonter la stigmatisation et de relever le défi d'un développement personnel harmonieux pendant l'enfance et l'adolescence dans un tel contexte.

Can J Neurol Sci. 2013; 40: 21-28

Frontotemporal dementia (FTD) is a neurodegenerative illness with early onset, before the age of 65 . This dementia syndrome has a more rapid decline than Alzheimer's disease (AD) ${ }^{1-3}$. Symptoms of FTD include marked behavioral, frontal executive, language, and motor changes. Caregivers at home with the patient often include school age children. There are currently no resources for older children, or for parents to know how to discuss the illness and its implications with their younger children.

Previous studies have demonstrated that caregiving for a host of physical and mental illnesses as a child can have negative effects, including restrictions on peer relationships, health problems, educational achievement and emotional stability ${ }^{4,5}$. Luscombe et al. showed increased adverse psychological and physical effects, inversely related to age, in young carers of young-onset dementia patients ${ }^{6}$. Gelman and Greer suggested that children providing care for a younger dementia patient, as is often the case in FTD, are vulnerable because the experience occurs during key developmental years and can lead to feelings of loss and anxiety over the cognitive decline of the parent, shame from the parent's behavior, confusion caused by parent- child role reversal, and fear of developing the condition themselves $^{7}$. However, there can also be positive effects ${ }^{4,5,7,8}$.

There have been no studies directly comparing the needs of young carers of dementia patients to those of young carers for patients with other terminal or chronic conditions. GonzalezSalvador et al showed that adult caregivers of AD patients have higher levels of stress and psychological morbidity compared with adult caregivers in other chronic illnesses ${ }^{9}$. That level of stress could be attributed in part to the behavioural symptoms, impairment in instrumental activities of daily living, and length of time providing care. Pinquart and Sorensen conducted a meta-

\footnotetext{
From the Rotman Research Institute (DF, TWC), Baycrest Centre for Geriatric Care; University of Toronto (TWC), Toronto; Young Carer's Initiative (MP, SB); Gilbrea Centre for Studies in Aging, McMaster University (GE), Hamilton, Ontario; Dalhousie University Geriatrics (CC, KR), Halifax, Nova Scotia; Honolulu (KRN), Hawaii. Received April 30, 2012. Final ReVisions Submitted July 17, 2012. Correspondence to: Tiffany Chow, Rotman Research Institute, Baycrest, 3560 Bathurst Street, 8th Floor Posluns Bldg., Toronto, Ontario, M6A 2E1, Canada.

Email: tchow@research.baycrest.org.
} 
analysis of 127 intervention studies with adult dementia caregivers and found that psychoeducational interventions had the broadest positive effect on caregiver knowledge, burden, depression, and subjective well-being versus other intervention types $^{10}$. These types of interventions use a group setting to present structured information about the illness and encourage interactive caregivers to interact in discussion and role playing exercises. Svanberg et al found that young carers of dementia patients were comparable to young carers for other adult illnesses, both in the tasks they perform and the outcomes they experience $^{4}$.

In prior work by this group, provision of support and information online was identified by FTD caregivers as very helpful ${ }^{11}$. Because the needs of children of different ages are not intuitively obvious to clinicians, researchers and service providers, we applied for and were granted funding from the Ontario Ministry of Health Alternative Funding Plan's Innovative Grants and the Canadian Institutes of Health Research-funded Canadian Dementia Knowledge Translation Network. Our aims were to hold focus groups with children of patients with FTD to learn about their experiences and what they had needed at various points in the patient's diagnostic process and course of illness. The first grant began in December, 2010, and the last grant period ended in February, 2012.

We intended for analysis of the focus group data to inform the creation of webpages - one for adolescent caregivers to patients with FTD and another for parents who need to discuss the illness with younger children who would not access the Web themselves.

\section{METHODS}

Caregivers from the United States (US) and Canada had identified themselves as parents of children affected by FTD and requested that they be contacted by author (TWC) if an opportunity for their children to voice opinions were to arise. This list received an invitation in early 2011 for children aged 819 to volunteer their participation in one two-hour focus group that would be held through Skype or regular telephone. Participants were able to invite other eligible young FTD caregivers to participate, but this was ultimately not used in recruitment to the two focus groups. Any respondents to the invitation contacted the focus group leader (Leader, KRN) directly, as TWC was the treating physician for the parents of some participants.

\section{Inclusion criteria were:}

1. Self-identification as an 8-19 year old caregiver to someone with a frontotemporal dementia (behavioural variant or primary progressive aphasia or corticobasal syndrome or progressive supranuclear palsy)

2. English-speaking

3. Able to access the internet or teleconference line to participate in the focus group

4. If under the age of 18 , must have co-consent from a parent or legal guardian

Recruitment began in February, 2011 and continued for three months. Nine potential participants (six boys and three girls aged 8-17) responded after the two focus groups had filled and were therefore not included in the data collection, but they were invited to beta-test the resulting website to provide feedback.

The Leader obtained informed consent by telephone or e-mail from international (Canadian and US) respondents. Specifically, participants were asked for permission to:

1) Tape-record the focus group session

2) Tabulate and analyze their anonymized responses, with potential for future publication

3) Contact them again later to provide feedback on the drafts of materials created (i.e., pertinent webpages, printed materials)

The semi-structured interview guide appears in Appendix A online. The guide itself was written to elicit a table of contents for the website and was not driven by theory, nor was it intended to generate theory. The Leader was a medical journalist who is herself a parent to two teenagers in a family touched by FTD; each of these two children participated in the focus groups separately. The Leader was not trained in methods of qualitative research and was not the co-author who ran the thematic analysis on the focus group transcripts (CC).

\section{Thematic Analysis}

The analysis followed the six steps of thematic analysis as outlined by Braun and Clarke ${ }^{12}: 1$. Familiarization with the data, 2. Generating initial codes, 3. Searching for themes, 4. Reviewing themes, 5. Defining and naming themes, and 6. Producing the report. A thematic analysis approach, which allows for the identification of themes within the dataset by means of a coding scheme, was used without the focus groups having followed qualitative methodology ${ }^{12}$.

The focus groups were digitally captured (audio) and transcribed to form a data corpus ${ }^{12}$. As the analyst did not collect the data, the first step was accomplished by initial reading and re-reading of the transcripts. The Leader's comments and instances in which she shared her own experience with the group or conversed with her own children directly about their family story (biased prompting) were struck from the transcripts during review by TWC and CC prior to thematic analysis, as they would direct the responses that followed from other participants. In some instances, the Leader would begin with an openly phrased question but then follow with narrowing questions. Nevertheless, our review of the resulting dataset revealed complex answers that were not easily categorized, i.e., there were rare Yes/No responses.

An initial coding scheme was derived from the dataset (see Appendix B online for coding dictionary). At this level, codes were applied to individual segments at the most basic level. With the data coded, theme areas were then identified, focusing on broader ideas than are represented by the individual codes.

The qualitative software package Atlas.ti ${ }^{13}$ facilitated the application of codes and organization of theme groups, as well as creating the theme-based query outputs (quotations from the text). All data, save for areas where the interviewer was wrapping up sessions or explaining the study process, were eventually categorized within one or more theme areas.

Codes were sorted and resorted into "code families" that represented potential theme areas. Once a candidate set of themes were prepared, the coded areas of text in each were 
reviewed to ensure the coherence of these choices, and of the themes in relation to the data and the project overall. At this point, the themes were able to be clearly defined and renamed if necessary, and work began to prepare the report.

\section{RESULTS}

Potential participants had difficulty agreeing on a date and time that did not conflict with their extracurricular activities or simply did not follow-up in the attempts to follow-up on scheduling. We ultimately distributed an email request to the parents of the potential participants asking for their assistance in convening the children. The focus groups, including children and adolescents from across several time zones in the United States and Canada were finally held from 3 to 5 p.m. EST in April, 2011 and from 4 to 6 p.m. EST in May, 2011.

The characteristics of the participants for the two focus groups are indicated in Table 1 . There were fourteen participants ranging in age from 11-18. They had an average of three years of living in a household with someone identified as a person with FTD, and 10/14 were girls.

\section{Theme Areas}

The analysis revealed seven overarching theme areas (often with subthemes):

Emotional Impact of Living with a Parent with FTD, Caregiving, Coping, Diagnosis, Relationships, Support and Symptoms. Single excerpts from the items coded within each theme appear in italics below the summaries of the theme areas; a larger set of excerpts appears in Appendix $\mathrm{C}$ online, and readers are encouraged to examine these to gain the children's perspectives.

\section{Emotional Impact of Living with a Parent with FTD}

Many participants discussed the negative emotional impact of living with a parent with FTD. While most references were to negative emotions (anger, embarrassment, fear, guilt, confusion and frustration), participants also offered positive emotions arising from the situation. These feelings were often linked to the event of diagnosis (see below).

P4: ... it feels really weird when like someone you know acts a certain way their whole life then all of a sudden they start changing and becoming a different person. It leaves a real lasting impression, and it does feel really weird... You try not to change your opinion of him, but since our family didn't know what he had at first, our opinion started to change. And that was kind of lasting and other people before they knew what he was diagnosed with, their opinion started to change too, because he was acting a different way than what he used to. And that kind of left a lasting impression on the people who don't talk to our family so much.

\section{Caregiving}

Participants talked about caregiving, discussing the specific tasks and activities required of them, as well as the rewards and challenges of this role. When participants discussed caregiving,

Table 1: Characteristics of focus group participants

\begin{tabular}{cccccccc}
\hline $\begin{array}{l}\text { Focus } \\
\text { Group }\end{array}$ & Family ID & ID & Gender & Age & $\begin{array}{c}\text { Family Member } \\
\text { Affected }\end{array}$ & $\begin{array}{c}\text { Approx. Years } \\
\text { With Diagnosed } \\
\text { Patient }\end{array}$ & Diagnosis \\
1 & A & P1 & F & 16 & Stepfather & 1 & FTD \\
1 & B & P2 & F & 15 & Father & 2 & FTD \\
1 & B & P3 & F & 11 & Father & 2 & FTD \\
1 & B & P4 & M & 18 & Father & 5 & FTD \\
1 & C & P5 & F & 11 & Father & 5 & FTD \\
1 & C & P6 & F & 15 & Father & 5 & FTD \\
2 & D & P7 & F & 14 & Father & 2 & FTD \\
2 & D & P8 & F & 11 & Father & 5 & FTD \\
2 & E & P9 & F & 17 & Mother & 5 & FTD \\
2 & E & P10 & M & 16 & Mother & 5 & FTD \\
2 & F & P11 & M & 16 & Father & 2 & (PPA) \\
2 & G & P12 & F & 14 & Grandfather & FTD \\
2 & G & P13 & F & 8 & Grandfather & 2 & FTD \\
2 & A & P14 & M & 18 & Stepfather & 1 & FTD \\
\hline
\end{tabular}


it was notably linked to areas such as the relationship with the patient, their relationship with the healthy parent (or family member), and strategies for coping with FTD.

Participants identified some of their main caregiving tasks and challenges. Tasks included physical support of the patient, such as helping with feeding and ambulating, and ancillary activities like providing help around the house through chores or communicating with healthcare professionals on behalf of the patient.

A variety of caregiving challenges were identified, such as trying to strike a balance between being a child and a supervising caregiver, struggling to exercise with the patient, and concern for the patient's safety. Caregiving took an emotional toll on the participants. They described the rewards that resulted from sharing a sentimental moment with the patient but also expressed guilt and self-blame at instances during which their patience wore thin. In a few cases, the participants found that their experience brought them closer to their families and made them better people. There was notable overlap with the areas of relationship with the patient and strategies for coping with FTD.

LEADER: How does it feel when you all are helping him physically?

P4: It's upsetting a little bit. But I feel good about it, because ... even though he may not recognize us at first, if we start to play with him, or we start cracking jokes, or we do stuff that's familiar to him, he'll smile and laugh a bit. And that makes it worth it.

\section{Coping}

In free discussion, participants expressed how they had personally dealt with the patient. Talk of coping strategies crossed into other theme areas such as how they handled their relationships with the patient and the healthy parent/family member, as well increasing knowledge about FTD and its negative impact on their respective families. The latter topic is described above in "Emotional Impact" and in the next section, "Diagnosis."

Directed Questions Pertaining to This Theme: When asked specifically if they had advice for other children on how to cope with their situation, participants discussed their personal stories about their parent/loved one who has FTD. Participants found that spending as much time as possible with the patient and reminiscing about old memories helped ease the burden of some encounters between child caregivers and their loved one with FTD by directing the focus of the interaction to pleasant topics that lacked conflict, and by allowing children to clarify mixed feelings about their loved one with strong memories of the person he or she had once been. Some of the activities that participants found useful included having simple conversations, watching TV or movies, going on walks, and taking family vacations. When asked about their feelings toward providing physical support, such as toileting, participants admitted they found it somewhat upsetting but felt good about being able to help.

Providing support for the rest of the family and healthy parent was important and could be accomplished by assuming more responsibility around the house and sharing household chores. They also found it helpful to channel their energy outside the home through sport, dance, choir and even volunteering.
Sometimes difficulties arose with outsiders who did not understand the illness; this demanded some problem solving from the participants. Participants found that outsiders had very little knowledge of FTD and often assumed that behavioural or personality changes were the result of the patient simply acting in a belligerent or unpleasant manner. Other issues included gossip and rumors among peers at school. Coping strategies ranged from simply ignoring people who were judgmental or unsympathetic to openly sharing information about FTD with those willing to listen.

They identified maintaining a positive yet realistic attitude toward the condition - as well as showing the patient compassion and patience - as important strategies to help cushion the impact of the disease.

P12: Well, when he's like watching shows or reading his books, we like to let him be, but once in a while our grandma wants us to go and like have some coffee with us or take him for a walk and that's like when we participate with him.

LEADER: And how does that go - is it enjoyable or is it challenging?

P12: Well, it's not really challenging or enjoyable. He's just silent. He doesn't really like conversation; he just likes to get to go where he needs to -

\section{Symptoms of FTD}

Participants talked about specific symptoms of FTD and the impact on the relationship with the patient and others. Some descriptions are difficult to limit to one symptom area, as symptoms may overlap (e.g., less affectionate toward family and general lack of motivation for self-care and prior interests). The discussion centered on symptoms such as personality and behavioral changes, and difficulties with communication, judgment, memory and emotion.

Although personality and behavioral changes in the patient were distressing, participants found some solace in being able to attribute the changes to an underlying disease. Several participants felt that the burden caused by personality changes often arose from the aforementioned conflict between the patient and outsiders, because outsiders were unsympathetic, illinformed, or unaware of FTD.

Communication difficulties were highlighted as one of the most difficult symptoms to cope with in FTD. During the course of illness, participants readily noticed difficulties in the patient's ability to communicate, including forgetting words, confusing the meaning of words, and very limited speech with answers often restricted to a "yes" or "no.". Disrupted communication restricted or even precluded meaningful interaction with the patient. In some cases, this was due to the patient's tendency toward social isolation and reticence. In other cases, speaking to the patient was unsuccessful because the patient's deteriorating memory did not allow for a sustained conversation. Some participants described a feeling of awkwardness resulting from these changes.

Participants commented on the level of insight and judgment shown by the patient. Most noticed that the patient still retained some idea of having an underlying disease, but had no appreciation for its changes to their behavior or any impact on others. 
Participants also discussed the negative impact of memory loss. Memory loss was difficult for the caregivers but also served as a source of frustration for patients themselves.

P11: ...P14 is ... absolutely right that there's a complete disconnect between... a language problem and a behavioral problem, because for example, with the specific thing my dad has - Primary Progressive Aphasiamany doctors have no idea even what it is. They have to look it up, apart from the neurologist who deals with it. But the thing with them is they hear the part, 'aphasia,' and they think, 'Oh, a language problem,' but a ton of other people think that since it's called 'aphasia' that the person can't really speak and it doesn't relate to behavioral changes, and it absolutely does.

\section{Diagnosis}

Participants talked about how and when they learned of the diagnosis, how this information made them feel and strategies employed by families or professionals in discussing this topic with them. This theme area overlapped notably with emotional impact of FTD and symptoms of FTD.

At the disease onset, several participants remembered noticing personality and behavioral changes in the FTD patients yet did not attribute them to a disease. In a few cases, the FTD patient required medical attention, and the diagnosis was brought to light by healthcare providers. However, virtually all participants were told of the diagnosis through discussion with the healthy parent, and in some cases, the patients themselves helped explain.

Participants unanimously agreed that sooner was better in terms of breaking the news. However, there was some debate about disseminating the information in its totality, especially concerning the prognosis. The prevailing opinion was that the approach should be tailored to the individual child based on age and maturity. Children should have the option of learning as much about FTD as they feel comfortable with, and that in some cases, details about the progression and overall prognosis should be provided incrementally.

Not all participants were able to remember the impact of the diagnosis, as many received the news at a young age. Most remembered the news triggering shock and confusion, but in retrospect, many felt a sense of relief to finally attribute the changes in the patient to a specific illness.

P1: I think the best way is to just tell [children] as soon as possible, because otherwise they're just going to see that their loved one is changing and they're not going to know why. They're going to think it's just them. So I think it's best to tell them as soon as possible, like when they find out, so everyone can know what's wrong and know it's a disease, and they can go on from there. Instead of trying to hide it or downplay it.

\section{Relationships}

Participants talked about how FTD impacted their relationship with the patient, as well as with the well parent/family member. This area had notable co-occurrence with coping strategies for FTD, as well as behavioral symptoms of FTD. Key areas of impact included interaction and communication, and perception and acceptance of the patient. Most felt that one of the biggest challenges in the evolving childpatient relationship was deterioration in communication. Although communication was often one-way, some participants found that spending quiet time with the patient was still mutually beneficial. Other caregivers felt that just seeing the patient smile or laugh provided its own sense of reward.

Personality and behavioral changes in the patient left a lasting impression on all participants. Several described the strangeness that accompanied witnessing the transformation of the patient at the disease onset. Compassion for the patient played an important role in the new relationship, and attributing the changes to the disease facilitated this acceptance.

Participants recognized the immense increase in responsibility falling on the healthy parent and the emotional and physical burden that resulted. They generally increased their appreciation and understanding of the healthy parent, and some developed stronger relationships with that parent. In several cases, the relationship changed to more of a partnership as the participants shared the burden of caregiving and household chores. Some also stressed the importance of the healthy parent maintaining a parental role in order to give young carers a sense of normality and stability.

P14:...With [my stepfather], it changed a lot on the outside because of the way he was behaving, but I just knew that whatever he was behaving like that wasn't logical or that wasn't...that just wasn't him. That's just something I accepted: 'Ok, this isn't his choice to be like this.' You know, he's under the influence of something horrible.

\section{Support}

Participants talked about the means and impact of the support they received. This included emotional sustenance, as well as the ability to receive and share information from family, friends and professionals. They also discussed their preferences for receiving that support - in person or via technology. This area had notable co-occurrence with emotional impact of FTD, coping, and relationships .

The majority of participants identified their healthy parent as the chief means of family support, followed by siblings and extended family. Important aspects of the healthy parent's role include providing information, emotional support, and a sense of stability.

Most participants found talking to friends a useful outlet. Although most friends had a very limited understanding of FTD, they were typically empathetic and willing to listen. The supportive role of friends ranged from directly helping the participant with the patient to simply providing relief in times of stress around the home.

Unlike support from family members and friends, participants felt somewhat disconnected from health professionals. Reasons included a lack of familiarity with the healthcare provider, and not receiving guidelines or recommendations on FTD at the doctor's office. Participants were asked the directed question, "Would you like to be at the doctor's appointments with parents/family members?" The majority of participants indicated that they would not want to 
Table 2: Links to Helpful Resources

\begin{tabular}{|c|c|}
\hline \multicolumn{2}{|l|}{ Young Carer Activity Support Groups } \\
\hline http://www.youngcarers.net/ & Help and advice for young carers \\
\hline http://hospicetoronto.ca/Page. asp?IdPage=9292\&WebAddress=hospice & Activities program designed for young carers \\
\hline http://recrespite.com/ & Offers recreational workshops \\
\hline \multicolumn{2}{|l|}{ Helping Young Carers Help the FTD Patient } \\
\hline http://alzheimers.org.uk/site/scripts/documents_info.php?documentID $=90$ & Advice for spending time with patients \\
\hline http://research.baycrest.org/chow-lab & How to handle difficult FTD behaviours \\
\hline \multicolumn{2}{|l|}{ What Psychologists Say About Young Carers } \\
\hline http://ambiguousloss.com and Ambiguous Loss and Loving Someone Who Has Dementia & Website and books by author Pauline Boss \\
\hline Parentification of the child: a case study of Bowlby's compulsive care-giving attachment pattern & $\begin{array}{l}\text { Article on compulsive caregiving my Malcolm West } \\
\text { and Adrienne Keller }\end{array}$ \\
\hline \multicolumn{2}{|l|}{ Learn More about Dementia } \\
\hline http://www.theaftd.org/ & Association for Frontotemporal Dementia \\
\hline http://www.mayoclinic.com/health/frontotemporal-dementia/DS00874 & \multirow[t]{3}{*}{ Facts about dementia } \\
\hline http://memory.ucsf.edu/ftd/ & \\
\hline http://www.ninds.nih.gov/disorders/ picks/picks.htm & \\
\hline \multicolumn{2}{|l|}{ Advice for Treating Young Carers } \\
\hline http://www.medicinenet.com/script/main/art.asp?articlekey=47165 & Getting the most out of a doctor's visit \\
\hline http://www.caringtoday.com/ & General advice for caregivers \\
\hline http://www.lifeandminds.ca/whendementiaisinthehouse/ts_sec4_2.html & Advice for sharing with friends of young carers \\
\hline
\end{tabular}

attend doctor's appointments for a variety of reasons, including the belief that they could not cope with what they would hear. In other cases, they felt it simply would not do any good for the child to attend. The latter notion was connected with the perception that few treatments, if any, were available for FTD. Participants also acknowledged that the decision to attend doctor's appointments depended on their own level of maturity or age.

When asked about obtaining support in-person or via technology, participants preferred conversations in-person but accepted technology as an alternate means of support that could be used in specific circumstances. The participants were also asked about the utility of attending a monthly support group. They generally agreed that while it could be beneficial, it depended largely on an individual's personal support needs. They suggested smaller groups over larger ones with groups stratified by age to facilitate comfort during discussion.

P5: I kind of get some support from my friends because they try to imagine what it's like. I think it's good to get support from your friends - just someone else. We get a lot of support from mom, but I think it's good to get support from other people, because sometimes it's just not a good time to talk to my mom about that stuff, or if it's just been a bad day. And you don't really want to ruin it for other people too, so you just have to talk to your friends.

As a result of the interview, some of the participants discovered that speaking about their situation was a positive experience. Several expressed interest in joining an online forum where they could share their experiences with other peers. One of the recognized benefits of a forum was that computers would provide an alternative means of expression which may be more appealing to tech-savvy teenagers.
P4: This is actually the first time that I think I've sat down with my sisters and had a big discussion about FTD, and all the things we were going through. I was wondering if this was the same for others. We never really talked about it before.

P2: Yeah, we've never really talked about this.

P3: This is the first time for us, too.

P1: I guess in the past I've had a couple conversations with my mom, my brother, and me, but we don't really talk about it at all or very much. My brother and I don't really talk about it together.

LEADER: I'm going to add to that; is this helpful or not? P4: Oh, for sure.

P2: Yeah.

P4: If not for the information, it's helpful to get things off your chest.

P4: Another good thing about a forum would be a lot of kids are more into computers - that's what they're comfortable with - so they might be more comfortable typing about it rather than talking about it.

Based on these responses, website content was developed and launched at url: www.lifeandminds.ca/whendementiaisinthe house on November 15, 2011. Prior to the launch participants were given the opportunity to confirm that important points from the focus groups were addressed with the website. Respondents appreciated the separation of content for parents from that for teens and the style of presentation. To our surprise, they suggested we add more text and information in future updates.

The webpages for teens are organized into five sections: "Doctor's Don't Know Anything About Dementia," "What Psychologists Say about You," "Advice from Kids Who Understand," "How to Get Help," and "Learn More about Dementia and Downloadable Resources." 
"Doctor's Don't Know Anything about Dementia" is titled after the consensus from participants about lack of support from healthcare professionals. This subsection attempts to empower young carers to request the help they need, by delineating the role of physicians and other healthcare workers in dementia, providing further education about dementing illnesses and FTD, and giving an overview of brain function and how it is disrupted by dementia. There are also suggestions for how to interact with a loved one with dementia, along with links to further content, e.g., sample day planners. We have included templates of letters that physicians can provide families to help explain dementia in social or legal situations (see Table 2 for links).

"What Psychologists Say about You" shares what professionals know about the responsibilities and challenges faced by young carers and gives advice for coping with the stress and feelings associated with caring.

"Advice from Kids Who Understand" provides information from the focus groups on coping with emotions, advice on extracurricular activities, and suggestions for spending time with a loved one with dementia.

"How to Get Help" makes recommendations to caregivers on how to share information about dementia with friends and outsiders, and advises friends on simple ways to support a child caregiver.

"Learn More about Dementia and Downloadable Resources" has further links to outside resources, such as the Association for Frontotemporal Degeneration and the Alzheimer Society.

\section{DisCUSSION}

In the United States, dementia accounts for the greatest share of young carer responsibility (Young Caregivers in the US Study). In Canada, early-onset dementia has been estimated to affect approximately 73,000 individuals (Personal Communication, Alzheimer Society of Canada, March 5, 2012). In the context of facilitated focus groups, 14 young carers of FTD patients shared their experiences and needs to inform the creation of a caregiver support website for teens. Although difficult to gather, the group discussion flowed quite readily, as participants found unexpected support in each other and relief from any isolation dementia had brought to their lives. Their comments did not seem to differ from the available literature on young carers in general, but the design of the study allowed for generation of an FTD-specific website.

Young carers took on the responsibilities of caregiving as part of their lives, yet never described them as a burden. They seemed to grow up more quickly, allowing for a more mature understanding of their priorities. Children tended to find relief in attributing the changes in their parent to an illness and made considerable effort to separate the disease from the parent. Otherwise, there would be a risk of creating an emotional boundary between self and the seemingly dangerous, unpredictable parent as a way of self-preservation (detachment). Nevertheless, children suffered from 'latent grief,' in that there was a loss of the prior parent-child supportive relationship despite the ongoing presence of the ill parent in the home leading to ambiguous sense of loss ${ }^{14,15}$.

Young carers often feared overwhelming the healthy parent with their own needs and pain. The young carers felt their priority was to protect the healthy parent. This can lead to compulsive caregiving, in which a person tends to assume a care provider role in all relationships. The role of being a young carer can influence future relationships in that they continue to act as caregivers in adulthood both within their families and other relationships. The same retrospective study reported that participants commented that they grew up too fast, leading to isolation from peers ${ }^{16}$.

The hesitation of young carers to communicate their needs and mixed feelings openly and honestly with their parents may have made it more difficult for family members to find common ground. Parents may help children best by providing an emotionally stable environment, with positive attitudes about caregiving. While remaining realistic about FTD, parents should be mindful that their own attitudes have tremendous impact on the children's state of mind. Parents also have the critical role of reassuring children that it is normal to experience a full range of emotional reactions, including frustration, anger, guilt and shame. The healthy parent-child relationship took on even greater importance in the context of FTD. We designed content encouraging well parents to debrief and receive emotional support from care providers and friends outside of the home to spare the children their most negative fears, dreads, and reactions to the illness. Children were more likely to ask for help after watching their healthy parent do the same first.

Successful interventions for young caregivers of dementia patients should offer both education and support, incorporate the entire family, and target the unique needs of the young carer. Presently, there is a paucity of supportive interventions for this group. The present study's findings are supported by several authors who have reported on supportive interventions for young carers. Among 50 young carers to adults with chronic illness, the most often cited request was for respite from caregiving ${ }^{17}$. Young carers felt that this could be achieved through services providing more assistance with activities of daily living and mobility for their sick relative and better support for their family. Parallel to our respondents, young carers in the context of earlyonset Alzheimer's disease benefit from involvement in outside activities, increased reliance on family and friends, and assuming more age-appropriate roles through structural family therapy ${ }^{7}$.

Although our findings have some validation in the prior literature, some limitations apply to our data collection. The focus group leader was herself a caregiver for a patient and that in each of the groups, one of the participants interviewed was a child of the leader. While the results of this data were limited to the experiences of the focus group participants themselves, we must also consider that biases or previous experiences of the leader may have played into the focus group process. Demographic characteristics of the participants were not analyzed but may have influenced results: for instance, $71 \%$ of the participants were female, and there may be differences in the caregiving role and experience based on the gender of the young carer or of the patient. Socioeconomic status of the participants was not taken into consideration and may not reflect the experiences of economically disadvantaged young carers.

\section{Conclusion}

Young caregivers saw the experience of tending to a parent with early-onset dementia as positive overall but identified 
opportunities for professionals to assist them in overcoming stigma and managing the challenge of balancing childhood and adolescent development within this context. We hope to report that our website, designed to address these issues, will prove itself a useful resource to this population.

\section{ACKNOWLEDGEMENTS}

This work was funded by the Ontario Ministry of Health Alternative Funding Plan's Innovative Grants, the Canadian Institutes of Health funding for the Canadian Dementia Knowledge Translation Network, and Women of Baycrest (TWC).

\section{REFERENCES}

1. Rascovsky K, Salmon DP, Lipton AM, et al. Rate of progression differs in frontotemporal dementia and Alzheimer's disease. Neurology. 2005;65:397-403.

2. Grinberg A, Lagunoff J, Phillips D, Stern B, Goodman M, Chow TW. Multidisciplinary design and implementation of a day program specialized for the frontotemporal dementias. Am J Alzheimers Dis Other Demen. 2008;22:499-506.

3. Chow TW, Binns MA, Cummings JL, et al. Apathy symptom profile and behavioral associations in frontotemporal dementia vs. Alzheimer's disease. Arch Neurol. 2009;66(7):888-93.

4. Svanberg E, Stott J, Spector A. 'Just helping': Children living with a parent with young onset dementia. Aging Ment Health. 2010 Aug; 14(6):740-51.

5. Dearden C, Becker S. Young Carers in the UK: The 2004 Report. 2004 [cited; 19]. Available from: http://www.lboro.ac.uk/ departments/ss/centres/YCRG/youngCarersDownload/YCRepor t2004\%5B1\%5D.pdf
6. Luscombe G, Brodaty H, Freeth S. Younger people with dementia: diagnostic issues, effects on carers and use of services. Int $\mathbf{J}$ Geriatr Psychiatry. 1998 May;13(5):323-30.

7. Gelman CR, Greer C. Young children in early-onset Alzheimer's disease families: research gaps and emerging service needs. Am J Alzheimers Dis Other Demen. 2011 Feb;26(1):29-35.

8. Stein JA, Rotheram-Borus MJ, Lester P. Impact of parentification on long-term outcomes among children of parents with HIV/AIDS. Fam Process. 2007 Sep;46(3):317-33.

9. Gonzalez-Salvador MT, Arango C, Lyketsos CG, Barba AC. The stress and psychological morbidity of the Alzheimer patient caregiver. Int J Geriatr Psychiatry. 1999 Sep;14(9):701-10.

10. Pinquart M, Sorensen S. Helping caregivers of persons with dementia: which interventions work and how large are their effects? Int Psychogeriatr. 2006 Dec;18(4):577-95.

11. Chow TW, Pio FJ, Rockwood K. An international needs assessment of caregivers for frontotemporal dementia. Can J Neurol Sci. 2011 Sep;38(5):753-7.

12. Braun V, Clarke V. Using thematic analysis in psychology. Qual Res Psychol. 2006;3(2):77-101.

13. Muhr T. Atlas.ti. 5.2 ed: Scientific Software Develeopment GmbH 2004.

14. Dempsey M, Baago S. Latent Grief: the unique and hidden grief of caregivers of loved ones with dementia. Am J Alzheimers Dis Other Demen. 1998;13(2):84-91.

15. Boss P. Ambiguous Loss: learning to live with unresolved grief. Boston: Harvard University Press; 2000.

16. Charles G, Marshall S, Stainton T. Demographics profiles and initial results from the British Columbia Young Carers Study. Relational Child and Youth Care Practice. 2010;23(4):64-7.

17. Moore T, McArthur M. We're all in it together: supporting young carers and their families in Australia. Health Soc Care Community. 2007 Nov;15(6):561-8. 